\title{
Inter-Worldview Education and the Re-Production of Good Religion
}

\author{
Marianne Moyaert ${ }^{\mathbb{D}}$ \\ Faculty of Religion and Theology, Vrije Universiteit Amsterdam, 1081 HV Amsterdam, The Netherlands; \\ m.moyaert@vu.nl
}

Received: 28 July 2018; Accepted: 17 September 2018; Published: 21 September 2018

\begin{abstract}
In this article, I focus on the increasing interest taken by European political and educational policy makers in inter-worldview education. My article has two parts. The first part consists of a document analysis of pivotal European publications on this and related issues. In the second and more critical part of this article, I make explicit my concerns about these European pleas for inter-worldview education. The main criticism that I present below is that the European policy on inter-worldview dialogue views the problem of intolerance too much as an individual problem that can and must be dealt with pedagogically, without recognizing that intolerance is just as much a structural socio-political problem. Important European policy documents, to be examined in the first part of this article, do not discuss how the way our societies are structured results in a sustenance of inequalities and in the marginalization of certain groups of people. At no point does these documents link inter-worldview education to the need "to examine the ideologies and structures of society critically," as a consequence the plea for dialogue loses some of its critical and transforming potential.
\end{abstract}

Keywords: inter-worldview education; Europe; tolerance; inequality; power

\section{Introduction}

Political and educational policy makers, on the European level, are increasingly taken an interest in inter-worldview education, the goal of which is to promote understanding between people who uphold different religious and non-religious worldviews. Inter-worldview education includes both religious and non-religious voices in the classroom and engages them in a dialogical learning process. Because it is not focused solely on people who belong to a particular faith tradition and based on the assumption that everyone has a 'worldview', i.e., a particular way of looking at the world, inter-worldview education aspires to be more inclusive than inter-religious or inter-faith education [1,2]. How this will play out concretely varies from country to country and depends on the relation between Church and State, national histories and sociological developments. My own reflections are influenced by the context in which I work, the Netherlands [3], but I assume my considerations may also give rise to thought for other European countries, that continue to be affected by Christian legacies while at the same time undergoing processes of secularization and pluralization. While a strong supporter of inter-worldview education myself-I work at a multireligious department of Religion and Theology, Vrije Universiteit Amsterdam, where I teach students with a variety of religious and non-religious backgrounds-I have my concerns about the way European policymakers frame their pleas for inter-worldview education.

My article has two parts. The first part consists of an analysis of a series of documents that have been published over the last two decades by the Council of Europe (Section 2.1) and by the Organization for Security and Co-operation (Section 2.2). My aim is to foreground the rationale these documents themselves give for the necessity of inter-world-view education. Whence this focus on education? Staying as close as possible to these documents themselves while also drawing on the 
reflections and considerations developed by European educationalist experts, like Wolfram Weisse, Gerdien Bertram-Troost and Robert Jackson, I relate the current plea for inter-worldview to the so-called 'resurgence of religion' and the end of the classical secularization thesis. I will show how these documents assume a binary sociological analysis (Section 2.3), according to which our European societies are currently undergoing both processes of secularization and pluralization and (Section 2.4) I will explain why, again according to these documents, in the face of the complexity of our secularized and pluralized society the need has arisen to invest in strong, i.e., dialogical tolerance.

In the second more critical part of this article, I make explicit my concerns about these European pleas for inter-worldview education. I develop a politico-philosophical analysis to (Section 3.1) spell out my suspicion about the claim that the dialogical classroom is a safe space characterized by equality and neutrality. (Section 3.2) According to me, such claims do not sufficiently reckon with the fact that inter-worldview education happens in a particular socio-political context that is marked by structural inequalities and uneven power relations between people with different worldviews. I will continue my critical analysis by showing that (Section 3.3) the binary sociological analysis, which runs as a current thread through these European documents has an 'equalizing effect' and covers up the inequality between majorities and minorities. I will argue that this binary sociology, is faulty and that it needs to be amended. (Section 3.4) Next, drawing on genealogies of religion, I surface the ideological assumptions that undergird modern Western conceptualizations of what religion is (and ought to be) and I foreground how the current European plea for inter-worldview education seems to be aimed at re-producing good religion, understood as liberal, privatized and interiorized religion, which is distinguished from bad religion, understood as dogmatic, ritualistic and materialistic religion. I will also spell out how this normative distinction ends up with the marginalization of those religious voices that do not fit the mold of good religion. It will not come as a surprise that Muslims especially suffer under this situation. The 'reproduction' of good religion is usually legitimized based on the assumption that good religion is peaceful and bad religion conflictual, an assumption that has been deeply ingrained in the European socio-political imagination since the so-called religious wars. In the final part (Section 3.5) of this article, I argue that precisely this assumption does not stand ground in the face of historical evidence.

\section{European Policy on Religious Education: A Document Analysis}

\subsection{The Organization for Security and Co-operation in Europe (OSCE)}

The first organization that has, since the turn of the century, looked at the importance of religious education is the OSCE. This organization, which has 57 members-including most European countries, Russia, Canada, and the United States-wants to promote the cooperation between these countries in military, economic, and humanitarian areas, with the ultimate goal of increasing security in the world. Set up during the Cold War, the OSCE has recently, via its Office for Democratic Institutions and Human Rights (ODIHR), been looking at religion and the importance of religious education, particularly in connection with its role in conflict prevention. This led to the publication in 2006 of the Toledo Guiding Principles on Teaching about Religions and Beliefs in Public Schools. This document is meant to assist both legislators, teachers, educators and officials in educational ministries. They offer "practical guidance for preparing curricula for teaching about religions and beliefs, preferred procedures for assuring fairness in the development of curricula, and standards for how they could be implemented" [4]. The title of this document refers to the history of the Spanish city of Toledo, a history that teaches both that there is an alternative to the discourse of the clash of civilizations and that this alternative is fragile. Living with diversity presupposes that society invests in tolerance and dialogue, just as that happened during the Andalusian "golden age". If that does not occur, then exclusion mechanisms, oppression, and even violence gain the upper hand-we can easily see what happened in 1492, when the Reconquista and the exiling of Jews from Spain signaled an end to that golden age [4]. 
Against the background of the history of Toledo, the OSCE expresses its concerns about the contemporary situation, particularly about the fact that in Europe today "misunderstandings, negative stereotypes, and provocative images used to depict others are leading to heightened antagonism and sometimes even violence" [4] (p. 9). That problem can be tackled via an educational program that prepares young people for a pluralistic society, where they will in any case have to work and live together with those of other faiths and worldviews. Thus, in its advisory function, the OSCE appeals to the different European countries "to address the root causes of intolerance and discrimination by encouraging the development of comprehensive domestic education policies and strategies and awareness-raising measures that 'promote a greater understanding of and respect for different cultures, ethnicities, religions or beliefs' and that aim 'to prevent intolerance and discrimination, including against Christians, Jews, Muslims and members of other religions" [4] (p. 9). In addition, these guiding principles primarily emphasize that it is important to provide neutral religious education that does justice to the various worldview perspectives in all their complexity without threatening the right to the freedom of religion [4] (p. 9).

\subsection{The Council of Europe}

The Council of Europe is an intergovernmental organization whose purpose it is to combat discrimination and intolerance against minorities, to safeguard human rights, and to promote the diversity of Europe. The Council was formed in 1949, one year after the publication of the Universal Declaration of the Rights of Man [5] (p. 5). It began very concrete campaigns against hate speech, for example, and to chart the unequal treatment of men and women on the work floor, and to condemn prejudice against peoples like the Roma. The Council of Europe includes not only countries from Europe, but also countries such as Russia, Turkey (other countries, such as Vatican City, are not members but only observers). One focus of this Council is education, which offers opportunities to work on human rights and to promote the cultural diversity of Europe and the interaction between people with different cultural backgrounds. The Council of Europe is a consultative body that can make recommendations which countries can use to adjust their laws.

For a long time, this Council avoided looking at the topic of religion, certainly in combination with education, and preferred to speak of intercultural education or dialogue. In 2002, however, after having been shaken awake by ' $9 / 11^{\prime}$ ', the Council launched a major project, The Challenge of Intercultural Education Today: Religious Diversity and Dialogue in Europe [6] (p. 7). That project was followed up by the European Year of Intercultural Dialogue, the publication of a widely consulted reference book for schools, [7] and a White Paper on Intercultural Dialogue [8]. Since then, religion-understood indeed as a cultural phenomenon-has become a core element of the European diversity policy, and dialogue is presented as a way of allowing young people to become acquainted with as many perspectives as possible so that they can appropriate the virtue of tolerance and respect.

In 2008, a Recommendation on the Dimension of Religions and Non-Religious Convictions within Intercultural Education (CM/Rec 2008-12) was published, according to which all member states were to include the study of religions in their curriculum. The intention of this recommendation is "to ensure taking into account the dimension of religions and non-religious convictions within intercultural education as a contribution to strengthen human rights, democratic citizenship and participation, and to the development of competences for intercultural dialogue" [9]. The recommendation also clearly states that intolerance cannot be remedied by knowledge alone; how people publicize their own worldview identity and relate to other traditions and their adherents must also be dealt with. This concerns, in particular:

- Developing a tolerant attitude and respect for the right to hold a particular belief, attitudes based on the recognition of the inherent dignity and fundamental freedoms of each human being;

- Nurturing a sensitivity to the diversity of religions and non-religious convictions as an element contributing to the richness of Europe; 
- Ensuring that teaching about the diversity of religions and non-religious convictions is consistent with the aims of education for democratic citizenship, human rights and respect for equal dignity of all individuals;

- Promoting communication and dialogue between people from different cultural, religious and non-religious backgrounds;

- Promoting civic-mindedness and moderation in expressing one's identity [9].

A few years later, in 2011, the Council of Europe set up an expert team to reflect on the importance of inter-worldview education and in particular to help the various countries apply these ideas of inter-worldview education in their local context [5] (p. 9). Educationalist expert Robert Jackson, who will return later in this article, took a leading role in this process and in 2014 published the document Signposts: Policy and Practice for Teaching about Religions and non-Religious Worldviews in Intercultural Education [5]. In addition to many terminological explanations on what religious literacy, religion, worldviews, spirituality, etc. mean, Signposts emphasizes that more knowledge is needed about worldviews (both religious and non-religious) but that knowledge alone is not sufficient:

Religion is not restricted to practices, artefacts and buildings. It is also necessary to attempt to understand the meaning of religious language as used by religious believers, including expressions of their beliefs, values and emotions. Such understanding requires knowledge, but it also requires certain attitudes and skills that raise-self-awareness and understanding of the beliefs and values of others, as well as values affirming human dignity. [5] (p. 21)

\subsection{From Secularization to Pluralization}

To get more of a grasp of this European attempt for inter-worldview dialogue, I want to probe deeper into why both the CoE as well as the OSCE, which until recently had little to no interest in religion let alone inter-worldview education, changed course. Why does a security organization become involved with religious education? What has changed? [5] (p. 3).

Until recently, many policy makers assumed that religion would gradually disappear from the public domain, a view that was entertained by numerous philosophers and sociologists. The assumption was that secularization, understood as the social differentiation of secular and religious affairs, would not only lead to the decreasing influence of the church on politics, science, and education but also to the marginalization of religion on the level of personal experience and practice. In brief, modernity would necessarily bring about a decline of religion. From this point of view, it is understandable that religion was not high on the political agenda. Religion was a kind of leftover from the past or, at best, something that concerned people in their private lives, and thus politics did not have to bother with it any more.

Today policymakers have come to realize that the secularization thesis does not quite capture what is happening in European societies. Due to various processes of globalization, "including the migration of peoples, and massively improved communication via the Internet," Europe is also undergoing processes of pluralization. In Signposts Robert Jackson says that:

"In world affairs, religion has become a topic of public discussion, for both positive and negative reasons. Utterances from religious leaders such as the Pope or the Dalai Lama are reported internationally, while the consequences of negative events, such as those connected with 11 September 2001 in the United States of America, continue to be felt globally and are reported widely in the media. Cultural and religious diversity are experienced in every country. No state is homogeneous culturally. ... Diversity within states is complex and connects with global as well as regional, national and local issues. All of these factors are associated with an increasing view that religion and belief are not purely private issues and should be part of discussion and dialogue within the public sphere". [5] (p. 16)

Continuing along these lines, Wolfram Weisse, for years the coordinator and chief researcher of an international project financed by Europe [10] affirms that the interest of political policy makers 
in religion stems from a sociological paradigm shift: from a policy that was rooted in the paradigm of secularization to a policy that, in addition to secularization also took the pluralization of society seriously. Religion is not simply disappearing but transforming. Consider in this regard the following passage from the already mentioned Reference Book:

"Few currently doubt that secularisation is an irreversible feature of our societies, but it has to be acknowledged that it has not removed all traces of the religious experience and references from our society. Such traces and references are found in diverse and new forms. Today the symbols and values associated with the great religious traditions are still part of collective memory. A broad majority of many people in many countries still claim to belong to a particular religion (even though more often than not this does not necessarily imply that they are practicising members). Secularisation undoubtedly led to a narrowing of the social scope of traditional faiths. However, many religious or spiritual groups have sprung up at the same time. The major migration flows, which have had their impact on most societies have highlighted more clearly than in the past the diversity of ways of seeing life and the world, as rooted in different systems of belief. Many sporadic or endemic conflicts around the world involve groups that identify themselves with specific religious labels". [11] (p. 19)

This quotation refers to the way processes of both secularization and pluralization transform religion, giving way to a diversity of worldview perspectives: ranging from adherents who belong to different world religions, to dual belongers, people who self-define as spiritual but not religions, atheists, and so on. This makes coexistence more complex [12] (pp. 32-40). This difficult coexistence is apparent from the fact that stereotypes, incorrect presentations, prejudices, misunderstandings, and lack of understanding are an indisputable reality in various European countries and are taking on more problematic forms. In view of this situation European policy makers ask how to give shape to a society that is characterized by worldview complexity. The question is: How can the European project of coexistence with its achievements be safeguarded against intolerance [4] (p. 11)?

\subsection{Towards a Call for Strong Tolerance}

In response to this question, both the OSCE and the CoE argue for an active diversity policy, with particular attention to inter-worldview dialogue. The CoE especially emphasizes that dialogue is the best way to educate a person in tolerance, but, conversely, it also holds that not investing in dialogue guarantees intolerance [8] (p. 9). To put it more strongly, without dialogue, according to the White Paper, it will be "difficult to safeguard the freedom and well-being of everyone living on this continent" [8] (p. 13).

This European call for dialogue is rooted in a liberal democratic tradition in which the government is neutral and impartial with respect to the various worldviews and at the same time defends the religious freedom of all citizens. Historically speaking this framework, which is cited in virtually all documents, was the political answer to the religious wars that ravaged Europe in the 16th and 17th centuries and still seems to be operative [13]. Even more, it functions as the condition for dialogue [14]. However, in spite of claims to neutrality, the liberal tradition is full of specific assumptions about what religion is and should be, about what the potential for violence religion contains, and about the place of religion in society. In European diversity policy, these assumptions are seldom critically questioned. In the second part of this article, I argue that these assumptions are much less self-evident than they are usually supposed to be and that they, if left unexamined, restrict the critical potential of dialogue in advance. I endeavor to surface ideological assumptions about religion that underly the liberal tradition of tolerance.To be able to undertake this critical analysis, it is important that we first look again at the narrative of religious violence, neutrality, tolerance, and freedom of religion. This story goes as follows. 


\subsubsection{The Religious Wars and the Liberal Tradition}

The religious wars that ravaged Europe in the 16th and 17th centuries showed how destructive interreligious conflicts can be. It is certainly no exaggeration to state that these religious wars are deeply inscribed in the collective memory of Europe, and that the memory of them resonates with the contemporary expressions of so-called religious violence. Three beliefs stem from that period: (1) religious authority and political power must be separate; (2) religion has an enormous potential for conflict; and (3) when left to themselves, believers with different beliefs will not be able to find agreement and thus a policy is needed that regulates the place of religion in society. The message is: vigilance-a notion that also runs through the contemporary diversity policy like a common thread.

The modern answer to the inter-Christian religious wars is political liberalism, which is characterized by a "constitutionally warranted sense of respect for the life and liberty of each individual, a concentration on equal rights, and affirmation of the worth of democratic government and moral pluralism [15]." Political liberalism divides coexistence into two spheres, the public and private spheres, and emphasizes the importance of individual freedoms, including religious freedom on the one hand and tolerance on the other. The government and its institutions are expected to display an attitude of neutrality, which means that it makes no evaluation of this or any other religion and does make any comment on religious beliefs or practices.

In addition to neutrality by the government, societies demand that citizens be tolerant of the various worldviews that are present in society. In principle, tolerance cannot be equated with neutrality (which we expect from the government); it is even opposed to it. The tolerant person thus disapproves of the belief of the other but nevertheless endures it. Tolerance, viewed in that way, is a bothersome virtue that implies grinding one's teeth. Ricoeur even calls tolerance a form of asceticism that should make living with difference possible [16].

\subsubsection{The Erosion of Tolerance and the Necessity of Strong Tolerance}

One of the current problems, highlighted by policy makes, is that the virtue of tolerance is subject to erosion and more and more people understand tolerance nowadays in terms of conflict avoidance. We tolerate what is strange insofar as we are not affected by it and to avoid problems we avoid the other. This is called weak tolerance in the CoE's White Paper and other documents: "Tolerance [in this weak] sense, ... equates quite simply to 'putting up with'—from a distance—-the fact that others may love as they wish even though they may not share our values or belong to the same cultural or religious group" [7]. Weak tolerance, according to this document, means that "we" concern ourselves with others as little as possible and avoid them as much as possible. Understood in that way, tolerance no longer means enduring a problem - the problem that what we hold dear is confronted with a conflicting belief-but implies a distance to and lack of interest in whatever is different. The result is indifference: whatever the other is concerned with leaves us completely cold, and involvement with the other is suspended.

According to the $\mathrm{CoE}$, this weak tolerance presents a serious problem. First, it leads from an indifference to a fundamental lack of knowledge about worldviews (religious and non-religious). Nowadays many people are religiously illiterate. Not only does this limit the ability to understand important historical and contemporary events and artefacts (art, literature, architecture, music, etc.) from European culture [4] (p. 19), this illiteracy is also fertile ground for negative prejudices and stereotypical concepts that can lead to tactlessness [17]. Many people simply lack the knowledge to understand what religious people believe, what they regard as sacred, why certain utterances or actions may be experienced as offensive. They lack the finesse to deal with religion in an appropriate way. They laugh at things that are not funny; they talk when they should be silent. The avoidance culture thus leads from weak tolerance to intolerance and conflict.

To prevent conflicts or to rise beyond them, weak tolerance needs to be transformed in Europe into strong tolerance, which goes much further than just accepting diversity; here tolerance takes the form of dialogue. To quote the CoE's White Paper one more time: 
Understood in a stronger sense, tolerance ... implies that we all may consider that our own convictions are true, good and valid for ourselves but that those of others are equally true and valid in their eyes and that it is not for us to pass judgment on their conception of what constitutes a good life. This is a long and gradual learning process, particularly when it comes to religious convictions which are based on absolutes and not on any social consensus which is always liable to review and reappraisal. [11] (p. 20)

Instead of a cult of avoidance as found in weak tolerance, strong tolerance thus pursues interaction, for one learns about other worldviews by engaging in a reciprocal encounter with people who belong to and identify with these different traditions [8] (p. 13). It is hoped that the inter-worldview education, in which students are exposed to perspectives and ways of life that differ fundamentally from theirs, can remove mutual distrust and thus strengthen the ability for tolerance [7] (p. 16).

\section{Critical Reflections on Europe's Call for Inter-worldview Dialogue}

In the second part of this article I develop several critical reflections on this call for strong tolerance, not because I do not believe in the importance of inter-worldview dialogue but because I want to reinforce the critical potential on inter-worldview learning. I am concerned that the way inter-worldview education is framed will favor students who belong to the majority at the cost of some minority students. The main criticism that I present below is that the European policy on inter-worldview dialogue views the problem of intolerance too much as an individual problem that can and must be dealt with pedagogically, without recognizing that intolerance is just as much a structural social problem. In my reading, the above-mentioned European policy documents do not discuss how the way our liberal societies are structured results in sustaining inequalities and in the marginalization of certain groups of people. At no time does these documents link inter-worldview education to the need "to examine the ideologies and structures of society critically," and as a consequence, I think their plea for strong tolerance loses its critical and transforming potential [18] (p. 89).

To support my argument, we first have to go back to the beginning of this article, i.e., to our binary sociological analysis. That is where, in my view, it already goes wrong. I will show that the binary sociological analysis of secularization and pluralization ignores the reality of unequal power relationships between the majority and minorities and that this has to do with, among other things, the fact that this analysis takes only two factors into account, that is secularization and pluralization. In my view, however, there is also a third factor, namely, cultural Christianity that requires our attention. I then note that political liberalism, with its pillars of religious freedom on the one hand and the neutrality of the government on the other, is assumed to be the basic condition for inter-worldview dialogue. It takes on the role of an almost invisible backdrop for dialogue. It is supposed to create a kind of neutral and thus safe space in which dialogue is made possible. Those assumptions, however, are problematic. After all, liberalism is also a worldview or ideology, with a specific concept of the human being and a specific concept of religion. In fact, the "neutral" space in which dialogue should develop is already "filled" with specific values that will lead their own lives if they are not included as a dimension in the space of encounter. More emphatically, if the liberal values are not critically examined, the call for strong tolerance runs the risk of serving intolerant discourses and practices, which silence cultural and religious minorities that differ from the liberal norm. Tolerance then becomes intolerant.

\subsection{The Rhetoric of Neutrality, Equality, and Mutuality}

In the European discourse on strong tolerance, the space for inter-worldview education is understood as a neutral space in which students meet each other as equals. The purpose is to learn about different worldview perspectives, to grow in mutual understanding, to cultivate tolerance, and-more ideally - the advancement of appreciation. All of this should contribute to more solidarity, inclusion, and social cohesion. Mutual tolerance, it is said, should make a modus vivendi possible that does not cover up the differences but recognizes and respects them, and thus enables an inclusive society to develop. The basic idea is that everyone has his or her own cultural and worldview identity and in 
that sense is an other. Thus, every student who is confronted with difference has the same task of learning more about other worldviews and to become proficient in dialogical skills.

This hymn to strong tolerance and in particular the equality and mutuality that it presupposes is not innocent, however. It obscures the reality that people who differ with respect to worldview often do not occupy an equal position in our society. In fact, not all students are other or different (or not, at least, equally so). Some students embody the norm of the dominant culture, whereas other students embody difference more. I think that the call for strong tolerance ignores or even covers up structural social inequalities. Let me foreground how this equalization works.

First, the binary sociological analysis that lies at the foundation of the European call for strong tolerance contributes to a kind of leveling of worldview differences. The reasoning goes as follows. The Church loses standing and importance wherever secularization increases. In the space that then arises, religion is transformed. A kind of tangle of worldview perspectives is made possible by processes of secularization and pluralization: there are Jews, Hindus, Muslims, Buddhists, liberals, Christians, post-Christians, atheists, adherents of a new spirituality, etc., a plurality of options that together color society. Everything that is conceivable is possible, but, in principle, not a single tradition, not a single perspective carries more weight than another.

Second, calls for strong tolerance are constantly framed in a political discourse that emphasizes the neutrality of the government as well as the individual right to religious freedom, which is a universal right. The educational task is to turn students into citizens who respect religious freedom, are tolerant when confronted with annoying differences, and become proficient in dialogical exchange. This presupposes a classroom in which no single religion is privileged and where each worldview perspective is treated equally. The teacher is supposed to embody that ideal of neutral impartiality and ensure that the safety of the classroom.

Third, inter-worldview education focuses primarily on the personal development and growth of students. The idea is that a lack of religious literacy and interaction leads to misunderstanding, intolerance, and conflicts. To promote coexistence, students need to learn to become proficient in tolerance, and that challenge awaits everyone. The problem of intolerance is basically seen as an individual problem that can be solved by a combination of knowledge and inter-worldview dialogue.

\subsection{The Inequality of Dialogue}

What this plea for strong tolerance obscures, in my view, is the fact that the school, the class, the teacher, and the students are already part of a sociopolitical constellation that is permeated with inequality, an equality that has to do with the dynamics or, better, the power imbalance between the majority and minorities. To the degree that the space for dialogue is a reflection of society, it is already characterized by its current values, norms, customs, and structures that are unique to the majority culture and in any case privilege it. In addition, the majority culture has the ability to make itself invisible and thus to not be recognized as a specific culture that is subject to discussion [19]. It represents the norm that is not questioned and the background against which other cultures, worldviews, and religions are presented as other. In reality, however, against this background, not everyone in the class is equally other and different, just as not everyone in society is. There are gradations of otherness and the degree of otherness is measured against the norm of the majority culture in particular. If this is not thematized as an essential part of the inter-worldview learning process, calls for strong tolerance-however nice they sound — can assume problematic, even subtly oppressive, forms.

To undergird this criticism, I propose a correction to the binary sociological analysis that constitutes the framework for the recent (European) political interest in religion and inter-worldview education. I argue that cultural Christianity should constitute a third factor, over against and in addition to secularization and pluralization. I thus do not assume a binary but a ternary or threefold sociological analysis of European societies [20]. While my subsequent reflections are influenced by the context where I work, the Netherlands, I assume they may also give rise to thought for other European 
countries, that continue to be affected by Christian legacies while at the same time undergoing processes of secularization and pluralization.

\subsection{From a Binary to a Ternary Analysis: Cultural Christianity}

According to the classical view of secularization, the separation of church and state made all citizens equal in the public domain, an equality that is safeguarded by the neutrality of the government. Processes of secularization have, without a doubt, weakened the sociopolitical position of Christianity, nevertheless, I think it would be wrong to conclude that, now that Christianity has lost its position of prominence, that it finds itself on an equal footing with other religious, spiritual, and areligious phenomena [21]. I agree with Marjolein van den Brink that:

"[t]he public sphere, although often understood as 'neutral' or 'secular' is not that neutral at all. ... [N]ot so very long ago, most people in Western European countries adhered to some form of Christianity. Logically, custom, organizational structures and other practices were built upon and adapted to the demands of the most dominant of these convictions. Even though many people have since turned 'secular', that is are no longer actively living according to the demands of their faith and maybe non longer religious at all, the weekly days off are still organized so as to accommodate the biblical day of rest". [15] (p. 214)

That privileged position is not acknowledged by those who have born and raised in Europe and thus remains under the radar when the neutrality of the public space and the government is discussed [15] (p. 214). In the classroom too, students who belong to the majority have certain privileges that students who belong to a religious minority are not given [22]. Those privileges can take on different forms, but they are definitely connected with a kind of normalization of cultural Christianity as part of sociopolitical life.

What privileges am I talking about here? First of all, it may be expected that the teachers will overwhelmingly come from the majority group and have been formed by cultural Christianity; that the academic year will follow the Christian calendar; that the literature that will be studied will often have a Western-Christian perspective (this is certainly so in the area of inter-worldview learning where academic literature is produced primarily by Christian theologians and religious educators); that it is obvious that the campus is set up and decorated in line with (cultural) Christian feasts (Santa Claus, Father Christmas, a Christmas tree, Easter eggs, etc.); and that students who are perceived as belonging to the majority will seldom be questioned about the why of their worldview identity. Christian privileges are usually not seen but simply assumed by those who enjoy them. They are invisible. "As with any form of privilege, the very invisibility to those who enjoy it makes the environment seem natural-just as a fish has no idea anything else exists besides water because it has never had to think about any other possibilities" [23] (p. 46). Furthermore, it is quite likely that the student population itself will also be a reflection of the societal majority-minority ratio, with proportionally more (cultural) Christians than non-Christians, and the teacher also often embodies and represents the majority culture. This also means that minorities (Buddhists, Hindus, Muslims, and Jews) often do not recognize themselves in what are compulsory subjects, have to ask permission to be absent from classes when they, for instance, have to say their prayers (and perhaps have to explain why that is important), have few role models, and, have to daily experience the numerous manifestations of cultural Christianity. They are much more often asked about their particular worldview identity and they are often expected to represent their tradition. While learning about (cultural) Christianity is often a question of daily survival/living for them, that is not the case for (cultural) Christians learning about other worldviews [24].

Viewing tolerance as a virtue that every individual has to cultivate in an equal and reciprocal way ignores this sociopolitical constellation. Of course, the world would be a better place if everybody got to the point where they stopped to think before speaking and bore with clenched teeth certain worldview expressions that are considered untrue, nonsensical, or even foolish. If, however, (post)Christian 
privileges are not acknowledged, thematized, and problematized, the inter-worldview dialogue itself can be subtly oppressive. Strong tolerance, in fact, plays too much to the advantage of the majority culture and thus to the disadvantage of religious and cultural minorities. As Riitaoja and Poulter state: "While minorities encounter the majority's viewpoint on a daily basis, the majority group is not always aware or appreciative of minority points of view. When trying to explain their experiences, minorities are subordinate and thus forced to use a language that is 'foreign' to their worldview. Inequality of different perspectives is therefore unavoidable" [19] (p. 91). To overcome or at least recognize this situation of inequality, the unmasking of privileges should therefore be part of inter-worldview education [15] (p. 214).

\subsection{Political Liberalism and the Distinction between Good and Bad Religion}

If we look at the dominant culture, yet another tradition needs to be taken into account, i.e., political liberalism itself, in particular the ideological presuppositions about religion it entails.

The heart of the modern liberal society is the individual, and not the government, Church, or the clan one belongs to. The individual is viewed as rational and autonomous, and, as rational and autonomous beings, people have the freedom and the right to map out their own lives. They can freely choose which faith they will follow and can live their lives as they please. Thus, they do not, like their (premodern) ancestors, have to follow paths that were preset for them, without their own choice and knowledge. As stated above, the government is not to say anything about how people give shape to their lives; it should remain neutral.

Liberalism is bound up inseparably with the Enlightenment tradition, which presents itself as liberation from the straitjacket that traditions can be. At bottom, it emits a distrust of tradition, heteronomy, and collectivity. Tradition contains the risk of restraint and limitation within itself, and that is precisely what liberalism wants to liberate the individual from. This also needs to be seen against the background of the religious wars that plagued Europe in the 16th-17th centuries, which made the potential for conflict in authoritative (religious) traditions painfully clear. These wars shook trust in religious convictions and authorities and anchored the idea that religion is dangerous deep in the collective European memory [13] (p. 727). The way to transcend this impasse was the emancipation from the religious powers and increasing independence of the various social domains. That is why secularization, viewed as a decrease in the social importance of religion, is often interpreted as a sign of emancipation, "that is, as a quasi-normative consequence of being a 'modern' and 'enlightened' European" [25] (p. 191). Although religion and religious commitments are, as such, not irreconcilable with liberal thinking, there does seem to be an (implicit) distinction between good religion and bad religion, a distinction that, by the way, has also found its way into academia [26] Good religion is rooted in autonomy, which means that the person in question is driven by considerations that come from within and by choices that he or she makes in complete freedom. A religious commitment must be self-chosen. Viewed in that way, religion is authentic. It agrees, of course, with the liberal value of equality and strives for as democratic an organizational structure as possible. Religious hierarchies, ritual demarcations, and certain exclusion mechanisms are problematic, certainly if they are related to gender, for example. Good religion is moreover is modest, as not too prominently present in the public space, and not too visible nor audible. Good religion keeps to the private sphere and is inwardly oriented. It has no need for frills or show and views all those externalities as historical-culturally determined and thus relative. It does not lose itself in this kind of detail but enables its adherents to focus on what is ultimately important; which cannot be captured in human images. It is striking that this good religion fits precisely into the profile of modern Protestant religion-the believer is turned inwards, focuses on his or her personal relation with the ultimate, emphasizes much more the individual search than the collective community, takes a critical reflective attitude toward authority and minimizes the external, i.e., the visible, tangible, edible, etc. aspects of religion.

Bad religion is associated with heteronomy instead of autonomy, with the collectivity of the community instead of with individuality, with prescribed traditional patterns instead of a path one 
has marked out of oneself, etc. Bad religion is visible, audible, smellable-it is not shy but draws all attention to itself. It is anything but modest and focuses too much on outward show. To put it even more strongly, attachment to visible and tangible religious particularities are associated with immaturity, premodernity, irrationality-in short, with unenlightened religion. Most European societies are permeated by these liberal ideas and consciously—but often unconsciously as well-the message is that more traditional ways of life are not modern, potentially oppressive, not emancipated, and they also run the risk of fundamentalism and fanaticism and thus of inter-worldview conflicts. With a view to the social cohesion of society (and its security!), it is reasoned, this bad form of religion must be domesticated.

This liberal oriented concept of religion, and primarily the normative distinction between good and bad religion is deeply embedded in the majority culture. In the spring of 2018, the news media are talking of a right-wing wave moving across Europe. This shift to the right is not limited to specific populist parties that are said to be openly racist but is also found in centrist parties, and, strikingly, certain themes from right-wing discourse are also found in some traditionally left-wing traditions. The notion has arisen that 'our' values and norms are under pressure and need to be protected and defended, and action needs to be taken. Thus, as is also the case in Belgium and the Netherlands (the two countries where I live and work), more and more voices are claiming that everything associated with a view that is based on being less free (i.e., less tolerant) cannot and may not be tolerated. The liberal society that is based on the virtue of tolerance needs to be defended against intolerance. According to political philosopher De Wit:

“During the last few decades we in Europe have indeed become accustomed to regard religion and religious identity as the inalienable private choice and self-creation of the individual; even institutional religion's traditional frameworks - such as churches and the passing down of doctrine-we now quickly tend to associate with the curtailment of freedom and intolerance". [27]

The concept of 'tolerant' clusters in this discourse with liberal, free thought, open, autonomous, rational, progressive, whereas 'intolerant' is associated with illiberal, closed, heteronomous, irrational, conservative. None of that can be tolerated if the liberal society is to be saved. Just as the political philosopher Wendy Brown states: “Defined against the unfree, intolerant peoples who menace us, a tolerant citizenry is a virtuous and free citizenry; and it is precisely this virtue and freedom that licences the violation of principles of tolerance and freedom in the name of security" [28] (p. 103).

If this normative distinction between good and bad religion is not problematized as being part of a particular liberal ideology, the danger arises that it can, without being explicitly examined, become an implicit educational ideal in whose light students are judged. As educators, we then risk contributing to the reproduction of the normative distinction between good and bad religion and the marginalization of those students who do not find themselves on what is implicitly or explicitly represented as the right side of the line. Atheists, Catholics, and Jews were also excluded from tolerance in the past because their beliefs and practices fell outside differences that could be tolerated, whereas today it is primarily Islam in Europe that is being targeted. The dividing line between tolerance and intolerance becomes very thin.

\subsection{Strong Tolerance and Religiously Inspired Violence}

The power of attraction and persuasion that the call for strong tolerance still retains needs, in my view, to be sought in the presupposed connection between religion and violence and the belief that education can heal religion (or, better, believers) of its/their potential for violence. Certainly, ' $9 / 11^{\prime}$ and the more recent terrorist attacks in Europe and elsewhere in the world have once again reinforced the image of religion as the main cause of violence. In the documents published by the CoE and OSCE too, pleas for strong tolerance refer time and again to these devastating events. 
As mentioned before the idea that religion is an ambiguous phenomenon stems from the so-called religious wars. ' $9 / 11^{\prime}$ ' has basically reawakened this idea and the related political conviction that religion needs to be domesticated, now by means of active tolerance. Recent historical research points out, however, that this view is too simplistic and that the religious wars of that time cannot be reduced to a religious conflict between Protestants and Catholics. Religion certainly did play a role in this conflict, but the idea that Protestants and Catholics killed each other purely for doctrinal issues is a myth that legitimates certain political choices, such as the privatization of religion, and also leads to a continuing imputation of religion in general and a political-pedagogical case for the domestication of religion. This is a point that both William Cavanaugh [29] and Karen Armstrong [30] make. Armstrong points out that "while there is no doubt that the participants certainly experienced these wars as a life-and-death religious struggle, this was also a conflict between two sets of state-builders: the princes of Germany and the other kings of Europe were battling against the Holy Roman Emperor, Charles V, and his ambition to establish a trans-European hegemony modelled after the Ottoman empire" [30]. If these so-called "religious wars" only concerned intra-confessional differences, then Protestants and Catholics would have been in completely different camps. However, that was not the case. Alliances changed as certain territorial or economic or political interests changed, and "Catholic France ... fought the Catholic Habsburgs, who were regularly supported by some of the Protestant princes." During these wars, "combatants crossed confessional lines so often that it was impossible to talk about solidly "Catholic" or "Protestant" populations" [30]. In his book The Myth of Religious Violence, William Cavanaugh also criticized the obviousness with which it is stated that religion leads to violence. He argues that it not that obvious at all "to separate a category called religion with a peculiar tendency toward violence from a putatively secular reality that is less prone to violence" [29] (p. 54).

Furthermore, the idea that religion leads to violence implies an opposition between religious and secular ideologies, whereby the latter are led by rationality and only resort to violence when it is justified and calculated. This view focuses attention in a one-sided way on religion as the problem and shoves secularization (and the privatization of religion) to the foreground as the solution to the problem. If all religions conform to the model of the individualized, privatized, and depoliticized modern form of religion, then there would be no more violence. It is forgotten that people have committed the greatest atrocities—one could think here of Nazism, Communism, capitalism, as well as on the way in which the political model of modern secularism in some countries is imported with violence and imposed with subsequent explosions of reactionary violence.

In addition, when religion is used as a scapegoat, other factors that also contribute to violent conflicts are ignored. People do not become entangled in violence because of only one thing; there is usually a complex nexus of factors that lead to violence, and religious disagreements are only one of those factors. Even when people or certain groups give their violence a religious framework themselves, a wider context needs to be sought. Going beyond abstract discussions on religion and violence, one of the tasks of inter-worldview education is, in my view, to look at very concrete cases and, using a complex analysis, to investigate what factors play a role in the outbreak of violent conflicts. Here I am also thinking particularly of socioeconomic and political factors. In this analysis of concrete conflicts-local or global-the question also needs to be asked as to who benefits from a certain social conflict being framed in terms of religion instead of, for example, those of economic inequality, discrimination, geopolitical power relationships, etc., and asking what other strategies there are to extinguish these or any conflicts and what role religion and dialogue can play in this.

\section{Conclusions}

At first glance, the turn to religion on a European level seems to be a development that interreligious educators, like myself, can only celebrate. If religion received hardly any attention for years, and certainly not in combination with education, that seems now to have changed. Religion, or more broadly, worldview, is back on stage, and it is not only acknowledged to be an important cultural factor in European society but is also being given an important place in the education of 
young people. The fact that strong tolerance or inter-worldview dialogue are now being seriously promoted should be like music to the ears of interreligious educators. Nevertheless, I think there are good reasons to exercise caution with respect to the European call for education in tolerance.

European policy bodies seem to see education primarily as a vehicle to counter the problem of misunderstanding, prejudice, and lack of appreciation, to teach students the value of tolerance, and thus also to safeguard the basic principles of liberal democracy. In that way, contributions can be made to the realization of an inclusive society where everyone is not only welcome but also recognized as an equal, regardless of his or her background, and exclusion on the basis of belief is not tolerated [31] (p. 269), [32] (p. 48).

European policy makers are right to focus on the function of education in passing on the shared norms, values, and structures on which liberal democratic society is based. My concern is that the socializing role of education will overshadow its critical potential. The final product of education in general and of inter-worldview education in particular is, in my view, not to socialize students but to teach them to engage in hermeneutical reflection and to ask critical questions of certain prevailing social presuppositions and power relationships. Only then can education realize its transforming potential and not simply reinforce the social status quo. However, until now I have not seen this critical function of inter-worldview learning treated in the European documents. That has to do with the fact that there is very little meta-reflection in these documents on the deeper ideological presuppositions that give direction to the call for strong tolerance. I have argued that calls for inter-worldview education cannot be seen apart from a broader sociopolitical context in which they function and gain traction. That wider context is not value-free or neutral but is already characterized by specific, often implicit age-old habits of mind concerning the nature of religion, the relation of religion to violence, and the place of religion in secular society as well as the distinction between good and bad religion. If these deeply rooted habits of mind remains unexamined, the risk arises that dialogical education will not make good on its liberating and transforming potential and that certain inequalities will remain.

Conflicts of Interest: The author declares no conflict of interest.

\section{References and Notes}

1. Bertram-Troost, G.D.; de Roos, S.A.; Miedema, S. Religious identity development of adolescents in religious affiliated schools. A theoretical foundation for empirical research. J. Beliefs Values 2006, 27, 303-314. [CrossRef]

2. Wielzen, D.; ter Avest, I. Interfaith Education for All: Theoretical Perspectives and Best Practices for Transformative Action; Sense Publishers: Boston, MA, USA, 2017.

3. How this inter-worldview learning can be given shape depends on the national and local context in which it can be implemented. This will be very different in France (the culture of laïcité) than in pillarized countries, like the Netherlands and Belgium, and again different in Spain, to mention only one other country. In particular, (religious) educators and interreligious scholars are being asked to work out the outline of an policy of active diversity, so that intolerance can give way to tolerance.

4. Organization for Security and Co-operation in Europe. Toledo Guiding Principles on Teachings on Religions and Beliefs in Public Schools. Available online: https://www.osce.org/odihr/29154?download=true (accessed on 7 July 2018).

5. Jackson, R. Signposts: Policy and Practice for Teaching about Religions and Non-Religious Worldviews in Intercultural Education; Council of Europe Publishing: Strasbourg, France, 2014.

6. Bîrzéa, C. The education policy perspective. In Religious Diversity and Intercultural Education: A Reference Book for Schools; Council of Europe Publishing: Strasbourg, France, 2007.

7. Council of Europe. Religious Diversity and Intercultural Education: A Reference Book for Schools; Council of Europe Publishing: Strasbourg, France, 2007. 
8. Council of Europe. White Paper on Intercultural Dialogue: Living Together as Equals in Dignity; Council of Europe Publishing: Strasbourg, France, 2008.

9. Council of Europe. Recommendation CM/Rec(2008)12 of the Committee of Ministers to Member States on the Dimension of Religions and Non-Religious Convictions within Intercultural Education. Available online: https: / / wcd.coe.int/ViewDoc.jsp?p=\&id=1386911\&Site=CM\&direct=truen (accessed on 7 July 2018).

10. The REDCo project, Religion, Education, Dialogue and Conflict: A contribution to Dialogue or a factor of Conflict in transforming societies of European Countries, (Funded under FP6-CITIZENS). Religious educators from eight different countries worked on this project: Norway, the Netherlands, France, Germany, Estonia, Russia, England, and Spain. In empirical research they measure the willingness for dialogue, in particular that of students aged 15-18 years, and they developed theories of inter-worldview learning and practical applications for promoting tolerance and dialogue skills.

11. Milot, M. The religious dimension in intercultural education. In Religious Diversity and Intercultural Education: A Reference Book for Schools; Council of Europe Publishing: Strasbourg, France, 2007; pp. 19-30.

12. Weisse, W. Religious pluralization and secularization in Continental Europe, with a focus on France and Germany. Society 2016, 53, 32-40. [CrossRef]

13. Foody, K. Pedagogical projects: Teaching liberal religion after 9/11. Muslim World 2016, 106, 719-739. [CrossRef]

14. Leirvik, O. Interreligious Studies: A Relational Approach to Religious Activism and the Study of Religion; Bloomsbury Academic: London, UK, 2014; pp. 33-52.

15. Van den Brink, M. Equals in faith-faith in equality. In Religious Pluralism and Human Rights in Europe: Where to Draw the Line? Loenen, M.L.P., Goldsmith, J.E., Eds.; Intersentia: Antwerpen, Belgium, 2007; pp. 211-218.

16. Ricoeur, P. The erosion of tolerance. In Tolerance between Intolerance and the Intolerable; Berghahn Books: Oxford, UK, 1996; pp. 189-202.

17. Jackson, R.; Miedema, S.; Weisse, W.; Willaime, J.-P. (Eds.) Religion and Education in Europe: Developments, Contexts and Debates; Waxmann: Munster, Germany, 2007.

18. Riitaoja, A.-L.; Poulter, S.; Kuusisto, A. Worldviews and multicultural education in the Finnish context-A critical philosophical approach to theory and practices. Finn. J. Ethn. Migr. 2010, 5, 87-95.

19. Wekker, G. White Innocence: Paradoxes of Colonialism and Race; Duke University Press: Durham, Germay; London, UK, 2016.

20. Weller, P. Balancing within Three Dimensions. Available online: http://derby.openrepository.com/derby/ handle/10545/622605 (accessed on 18 September 2018).

21. Arthur, J. Intercultural versus interreligious dialogue in a pluralist Europe. Policy Future Educ. 2011, 9, 74-79. [CrossRef]

22. McIntosh, P. White Privilege: Unpacking the Invisible Knapsack. Available online: http:/ / code.ucsd.edu/ pcosman/Backpack.pdf (accessed on 7 July 2018).

23. Schlosser, L. Christian privilege: Breaking a sacred taboo. J. Multicult. Couns. Dev. 2003, 31, 44-51. [CrossRef]

24. Larson, M.H.; Shady, S.L. Confronting the complexities of Christian privilege through interfaith dialogue. J. Coll. Character 2012, 13, 2-8.

25. Asad, T. Formations of the Secular: Christianity, Islam, Modernity; Stanford University Press: Stanford, CA, USA, 2003.

26. Arweck, E.; Keenan, W. (Eds.) Materializing Religion: Expression, Performance and Ritual; Ashgate: Aldershot, UK, 2006.

27. De Wit, T. Between indifference and the regimes of truth. An essay on fundamentalism, tolerance and hypocrisy. Philosophia 2016, 44, 689-704. [CrossRef] [PubMed]

28. Brown, W. Regulating Aversion: Tolerance in the Age of Identity and Empire; Princeton University Press: Princeton, NJ, USA; Oxford, UK, 2006.

29. Kavanaugh, W. The Myth of Religious Violence: Secular Ideology and the Roots of Modern Conflict; Oxford University Press: Oxford, UK, 2009.

30. Armstrong, K. The Myth of Religious Violence. Available online: https:/ / www.theguardian.com/world/ 2014/sep/25/-sp-karen-armstrong-religious-violence-myth-secular (accessed on 7 July 2018). 
31. Davison, J.; Franz, D. Religious pluralism and civil society. In A Nation of Religions: The Politics of Pluralism in Multireligious America; Prothero, S., Ed.; University of North Carolina Press: Chapel Hill, NC, USA, 2006; pp. 256-273.

32. Byrne, C. Freirean critical pedagogy's challenge to interfaith education: What is interfaith? What is education? Br. J. Relig. Educ. 2011, 33, 47-60. [CrossRef] 